\title{
Body Image Discrepancy and Body Mass Index among Chinese University Students in Hong Kong 香港大學生身體質量指數與身體形象差異的概況
}

\author{
Siu Kuen Robert NG \\ Physical Education Unit, Faculty of Education, \\ The Chinese University of Hong Kong, HONG KONG
}

吳兆權

香港中文大學體育部

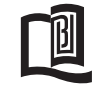

\begin{abstract}
Introduction: The purposes of this study were to examine (a) the relationship between Body Mass Index (BMI) and the perception of body image, (b) the body satisfaction level (BSS), and (c) the most satisfied and dissatisfied body part. Methods: 588 university students (aged: $20.0 \pm 2.2$ years; BMI: $20.3 \pm 2.8 \mathrm{~kg} / \mathrm{m}^{2}$ ) from four universities in Hong Kong indicated their perceived 'ideal' and the 'healthiest' male and female figure from 9-figure rating scale. Body Image Discrepancy (BID) between their 'current' and 'ideal' figure was calculated. Results: Men reported significantly higher level of BSS than women. BMI correlated with BSS in women $(\mathrm{r}=-263, \mathrm{p}<.01)$ but not in men; BMI correlated with BID in women $(\mathrm{r}=.446$, $\mathrm{p}<.001)$ and men $(\mathrm{r}=587, \mathrm{p}<.001)$. Most respondents indicated 'no part' as their most satisfied body part. Men and women stated their most dissatisfied body part was abdomen and thigh respectively. BSS was the highest in normal weight men and underweight women. Overweight respondents rated significantly larger figure as their 'ideal' size than their underweight and normal weight counterparts. Conclusions: An increase in BMI aggravates an increase in their desire to be thinner. It is necessary to help university students in Hong Kong to develop a healthy and realistic body image.
\end{abstract}

\section{摘 要}

探討大學生(1)身體質量指數(BMI)與身體形象差異的關係; (2)身體滿意度； (3)最滿意和最不滿意自己身體部份。588位大學生 從香港四所大學在 9 個由瘦至肥的男女剪影公仔中選擇(1) “理想” 和 “最健康” 的男女體型; (2)代表自己 “現在” 和 “理想” 的體 型來計算出身體形象差異。女性的身體滿意度比男性低並與BMI成反比。大多數指無最滿意的身體部份, 男女分別最不滿意腹部 和大腿。正常體重男士和過輕女士最滿意自己身體。總結, BMI與減磅意欲成正比。

關鍵詞：身體質量指數；身體形象差異；滿意度

\section{Introduction}

Body image relates to loose mental representation of the body's size, form, and shape (Thompson, Heinberg, Altabe, \& Tantleff-Dunn, 1999). It has two dimensions: attitudinal and perceptual (Flynn \& Fitzgibbon, 1998). The former examines the feelings and thoughts one has about the physical body, such as body satisfaction, body weight, and a feeling of attraction. The latter explores the accuracy of body size estimations and weight classification according to medical standards. Some researches indicate that body image perception and preferences not only relates to gender, age and 
body mass index (BMI), but also to race and ethnicity (Ricciardelli \& McCabe, 2001; Wright \& Whitehead, 1987). Body dissatisfaction occurred when there is a discrepancy between their perceived and their ideal body shape (Kemper, Sargent, Drane, Valois, \& Hussey, 1994). It concerns the global body image as a whole as well as specific body parts such as hip width, which may push nonobese individuals to weight control and eating disorders (Bailey, Goldberg, Swap, Chomitz, \& Houser, 1990; Singh, 1994).

Hong Kong, stands on the southeastern China, was a former British colony. It represents a unique fusion of Oriental and Western cultures where the old and the new live side by side. In traditional Chinese culture, plumpness symbolizes prosperity and longevity whereas thinness associated with poverty, bad fortune, and ill-health (Lee, Ho, \& Hsu, 1993; Lee, Leung, Lee, Yu, \& Leung, 1996). A most parents believe that fat children are the symbols of good health, higher status and fertility (Brown \& Konner, 1987; Bush, 2003; Cogan, Bhalla, Sefa-Dedeh, \& Rothblum, 1996). Chinese gods are always portrayed as 'fat' (Lee, 1999). However, this Chinese notion of prestige and beauty has been changed as the representation of attractiveness as a thin, fit body shape for females (Wiseman, Gray, \& Mosimann, 1992) and a lean muscular physique for males (Leit, Pope, \& Gray, 2001) was strongly promoted through advertising and mass media.

The college-age population is a transition period from adolescents to adult with independent exploration. This unique period relates to social and peer pressures to fit a societal picture and conform to the cultural expectation (Basow, Foran, \& Bookwala, 2007; Davis, Karvinen, \& McCreary, 2005; Nelson, Hughes, Katz, \& Searight, 1999). Dieting, body dissatisfaction and disordered eating and exercise behaviours are well documented among male (Drummond, 2002; O’Dea \& Abraham, 2000) and female (Crawford \& Worsley, 1988; Drenowski, Yee, Kurth, \& Krahn, 1994; Hill, 2002; Kenardy, Brown, \& Vogt, 2001) university students worldwide.

The relationship between the body image perception and BMI was investigated among university students in Japan and Korea (Sakamaki, Amamoto, Mochida, Shinfuku, \& Toyama, 2005), Germany and Lithuania (Stock, Kucuk, Miseviviene, Petkevicience, \& Kramer, 2004), Brazil (Kakeshita \& Almeida 2006), Eastern United States (Neighbors \& Sobal, 2007) and India (Priya, Prasanna,
Sucharitha, \& Vaz, 2010). There is a rare study of body image among college students in Hong Kong. $\mathrm{Ng}$ and Lin (2009) studied the satisfaction level of body image among 150 university students. They found that 23.9\% of men and $43.0 \%$ of women were dissatisfied with their body shape and $28.2 \%$ of men and $45.6 \%$ of women wanted to be thinner. Further investigation is necessary to explore the relationship between BMI and their perception of body image among university students in Hong Kong. The purposes of this study are to investigate: 1) the relationship between different weight status as measured by BMI and the perception of body image and health among university students; 2) their body shape satisfaction level; 3) their most satisfied and dissatisfied body part; 4) their most concern to perceive their body fatness.

\section{Methods}

A convenience sample of 596 students from four universities in Hong Kong participated in the study. They completed a one-page Chinese self-administered questionnaire anonymously which consisted of three sections: 1) body shape identification; 2) self rating of their body shape; 3) biographic information. The internal consistency of the questionnaire was from 0.77 to 0.81 .

\section{Body Shape Identification}

Body shape was assessed using a figure rating scale (FRS) (Stunkard, Sorensen, \& Schulsinger, 1983). The FRS consists of nine male and female schematic figures, ranging in size from (1) to (9) which representing very thin to very obese respectively. Previous research has found good overall FRS validity (Stunkard, Sorensen, \& Schulsinger, 1983) and test-retest reliability for undergraduate college student, ranging from 0.55 to 0.92 (Thompson \& Altabe, 1991). Respondents were asked to select one picture that fit best to each of the following: the 'healthiest' and 'ideal' body shape for men and women, their 'current' and 'ideal' body shape. Body image discrepancy (BID) was calculated by subtracting their perceived 'current' status from their 'ideal' body size (Fallon \& Rozin, 1985; Rozin \& Fallon, 1988; Thompson, Heinberg, Altabe, \& Tantleff-Dunn, 1999). This simple measure of BID has been utilized in body image study with demonstrated reliability and validity (Kemper, Sargent, Drane, Valois, \& Hussey, 1994). 


\section{Self Rating of their Body Shape}

Their level of body shape satisfaction (BSS) was assessed using a five-point Likert scale ranging from (1) very dissatisfied to (5) very satisfied. They reported their self-perceived body type from very fat to very thin. Their most satisfied and dissatisfied body part was stated. Finally, they listed five out of ten criteria to assess their body shape.

\section{Biographic Information}

Their gender, age, body weight and height were self-reported. BMI was calculated using selfreported body weight and height. Research has shown that self-reports are highly correlated with actual heights and weights, and are sufficiently valid to use in epidemiological and survey studies (Bowman \& DeLucia, 1992; Davis \& Gergen, 1994; Villanueva, 2001). The sample was divided into three BMI categories according to WHO/IASO/IOTF (2000): underweight $(<18.5)$, normal weight $(18.5-22.9)$, and overweight $(>23)$

\section{Statistical Analysis}

All data were analyzed using Statistical Package for the Social Sciences (Windows version, 20.0; SPSS, Chicago, IL). In phrase one, a univariate analysis was carried out to compare their level of BSS between genders of the respondents. In phrase two, Spearman's rho correlation analyses were used to examine the relationship between respondents' BMIs, BBS and BID separately for men and women. In phrase three, a series of univariate tests was conducted to compare 1) their perceived the 'ideal' with the 'healthiest' figures of men and women, 2) their 'ideal' figure with their perceived 'ideal' figure for the same gender. In phrase four, a series of analysis of variance (ANOVA) was performed to investigate any significant differences among male and female respondents with the three BMI categories on 1) my 'ideal' body shape, 2) the perceived the 'healthiest' and the 'ideal' body shape for men and women. Finally, a $3 \times 2$ factorial ANOVA was conducted to examine the effects of three BMI categories (underweight versus normal weight versus overweight) and gender (women versus men) on their BSS. An alpha level of 0.05 was employed for all statistical tests.

\section{Results}

Eight out of 596 respondents did not indicate their gender, data from 588 respondents were used for further analysis. 296 men (mean age: $20.2 \pm 2.3$ years; mean BMI: $20.9 \pm 2.7$ $\mathrm{kg} / \mathrm{m} 2$ ) and 292 women (mean age: $19.9 \pm 2.0$ years; mean BMI: $19.8 \pm 2.7 \mathrm{~kg} / \mathrm{m} 2)$ participated in the study. For men, $29.4 \%$ were dissatisfied and $24.3 \%$ were satisfied with their body shapes, $28.7 \%$ and $38.5 \%$ of them perceived they are fat and thin respectively. For women, 35.6\% were dissatisfied and $16.5 \%$ were satisfied with their body shapes, $49.8 \%$ and $22.3 \%$ of them perceived they are fat and thin respectively. The results of a univariate analysis indicated that males reported significantly higher level of body satisfaction than females $(\mathrm{t}=2.20, \mathrm{df}=586, \mathrm{p}<.05)$. BID was positively correlated with BMI in men $(\mathrm{r}=.587$, $\mathrm{p}<.001)$ and women $(\mathrm{r}=.446, \mathrm{p}<.001)$. Significant negative correlation was found between BMI and BSS in women $(\mathrm{r}=-.263, \mathrm{p}<.01)$ whereas no significant correlation was discovered between BMI and BSS in men $(\mathrm{r}=-.058, \mathrm{p}>$ $.01)$. Table 1 showed that the satisfaction level of body shape decreased with increasing BMI in female respondents. The desire to be thinner increased with increasing BMI for both genders. 
Table 1. Demographic Information, the Body Shape Satisfaction Level, and Self-perceived Body Shape of the Respondents.

\begin{tabular}{|c|c|c|c|c|c|c|}
\hline BMI categories & $\begin{array}{l}<18.5 \\
n=91\end{array}$ & $\begin{array}{l}\text { Female } \\
18.5-22.9 \\
n=175\end{array}$ & $\begin{array}{l}>23.0 \\
n=26\end{array}$ & $\begin{array}{l}<18.5 \\
n=51\end{array}$ & $\begin{array}{c}\text { Male } \\
18.5-22.9 \\
n=188\end{array}$ & $\begin{array}{l}>23.0 \\
n=57\end{array}$ \\
\hline BMI $\left(\mathrm{kg} / \mathrm{m}^{2}\right) \quad($ mean \pm SD $)$ & $17.3 \pm 0.9$ & $20.2 \pm 1.2$ & $25.8 \pm 3.1$ & $17.3 \pm 0.9$ & $20.6 \pm 1.2$ & $25.1 \pm 1.8$ \\
\hline Age (years) $\quad($ mean $\pm \mathrm{SD})$ & $19.8 \pm 1.9$ & $19.8 \pm 2.0$ & $20.7 \pm 2.6$ & $19.7 \pm 1.6$ & $20.2 \pm 2.3$ & $20.8 \pm 2.8$ \\
\hline Dissatisfied with their body shape & $25.3 \%$ & $36.6 \%$ & $65.4 \%$ & $43.1 \%$ & $20.2 \%$ & $47.4 \%$ \\
\hline Satisfied with their body shape & $25.3 \%$ & $12.5 \%$ & $11.5 \%$ & $13.7 \%$ & $30.8 \%$ & $12.3 \%$ \\
\hline Self-perceived body type as thin & $54.5 \%$ & $8.6 \%$ & $3.8 \%$ & $88.3 \%$ & $36.7 \%$ & $0 \%$ \\
\hline Self-perceived body type as fat & $14.4 \%$ & $62.3 \%$ & $88.5 \%$ & $0 \%$ & $20.2 \%$ & $82.5 \%$ \\
\hline \#The desire to be thinner & $31.9 \%$ & $75.7 \%$ & $88.5 \%$ & $5.9 \%$ & $23.9 \%$ & $80.7 \%$ \\
\hline
\end{tabular}

\# The desire to be thinner was calculated from the positive value of BID

$\mathrm{BID}=$ My 'current' minus my 'ideal' figure

The top five most satisfied body parts reported by female respondents in descending order was: no part (23.0\%), shoulder $(15.6 \%)$, calf $(14.2 \%)$, waist $(13.1 \%)$ and neck $(9.9 \%)$; while their top five most dissatisfied body parts were thigh (26.5\%), abdomen (17.0\%), calf (13.8\%) waist (10.6\%) and no part (8.8\%). Male respondents indicated their top five most satisfied body parts were no part (23.9\%), arm (18.4\%), calf $(11.9 \%)$, shoulder (11.6\%), and chest (8.2\%), whereas their most top five dissatisfied body parts were abdomen (25.0\%), no part (19.9\%), chest $(12.0 \%)$, thigh $(10.6 \%)$, and waist $(7.9 \%)$. The most significant male (18.7\%) and female (19.2\%) respondents concerned most about their weight status to assess their body shapes.

Results of a series of univariate tests showed that male respondents stated significantly larger figures as their perceived the 'ideal' and the 'healthiest' male and female figures than their female counterparts. The 'healthiest' male figure: $\mathrm{t}=2.872, \mathrm{df}=579, \mathrm{p}<.05 ;$ The 'healthiest' female figure: $\mathrm{t}=2.106, \mathrm{df}=581, \mathrm{p}<.05$; 'ideal' male figure: $\mathrm{t}=4.758, \mathrm{df}=579, \mathrm{p}<.001$; 'ideal' female figure: $\mathrm{t}=6.110, \mathrm{df}=582, \mathrm{p}<.001$.

Results of a series of t-tests showed that the sizes all respondents chose to represent the 'healthiest' figure for both genders were always significantly larger than the sizes they chose represent the 'ideal' figure in both male and female groups. Male figure: (for underweight men: $\mathrm{t}=48.43$, df $=50, \mathrm{p}<.001$; for underweight women: $\mathrm{t}=58.01, \mathrm{df}=87, \mathrm{p}<.001$; for normal weight men: $\mathrm{t}=78.68, \mathrm{df}=184, \mathrm{p}<.001$; for normal weight women: $\mathrm{t}=63.09$, df $=172, \mathrm{p}<$ .001 ; for overweight men: $\mathrm{t}=51.53$, df $=56, \mathrm{p}<.001$; for overweight women: $\mathrm{t}=31.88$, $\mathrm{df}=25, \mathrm{p}<.001$ ). Female figure: (for underweight men: $t=39.97, \mathrm{df}=$ $50, \mathrm{p}<.001$; for underweight women: $\mathrm{t}=51.14, \mathrm{df}=$ $90, \mathrm{p}<.001$; for normal weight men: $\mathrm{t}=69.66$, df $=183, \mathrm{p}<.001$; for normal weight women: $\mathrm{t}=77.42$, $\mathrm{df}=173, \mathrm{p}<.001$; for overweight men: $\mathrm{t}=45.31, \mathrm{df}$ $=56, \mathrm{p}<.001$; for overweight women: $\mathrm{t}=30.61, \mathrm{df}=$ $25, \mathrm{p}<.001)$.

There was a significant discrepancy between their 'ideal' figure and perceived the 'ideal' figure for the same gender. Male respondents reported significantly larger sizes of their 'ideal' than the sizes they chose represent the 'ideal' male figure $(\mathrm{t}=107.78$, df $=295, \mathrm{p}<.001)$, whereas female respondents rated larger sizes of perceived the 'ideal' female figure than their 'ideal' one $(t=76.94$, df $=291, \mathrm{p}<.001)$.

Table 2 showed the results of a series of one-way ANOVA revealed significant difference among male respondents $\mathrm{F}(2,293)=11.03, \mathrm{P}<$ .01 and female respondents $\mathrm{F}(2,288)=7.55, \mathrm{P}<$ .01 with the three BMI categories on my 'ideal' body shape. Post-hoc Scheffe's tests showed that overweight men and women rated larger figures as their 'ideal' size compared to their normal weight and underweight counterparts. However, there were no significant differences among (1) male 
respondents with the three BMI categories on: 'ideal' male body shape $\mathrm{F}(2,291)=0.81, \mathrm{P}=.09$, the 'healthiest' male body shape $\mathrm{F}(2,290)=2.42, \mathrm{P}$ $=.09$, 'ideal' female body shape $\mathrm{F}(2,289)=0.65$, $\mathrm{P}=.52$, the 'healthiest' female body shape $\mathrm{F}(2$, 289) $=0.25, \mathrm{P}=.78 ;$ (2) female respondents with the three BMI categories on: 'ideal' male body shape $\mathrm{F}(2,284)=0.069, \mathrm{P}=.93$, the 'healthiest' male body shape $\mathrm{F}(2,285)=2.49, \mathrm{P}=.84$, 'ideal' female body shape $\mathrm{F}(2,289)=1.54, \mathrm{P}=.22$, the 'healthiest' female body shape $\mathrm{F}(2,288)=0.84$, $\mathrm{P}=.93$.
Finally, the results of the $2 \times 3$ ANOVA indicated that there was significant effect of BMI categories (underweight $\mathrm{M}=2.89, \mathrm{SD}=0.78$; normal weight $\mathrm{M}=2.94, \mathrm{SD}=0.77$; overweight $\mathrm{M}=2.58, \mathrm{SD}=0.77), \mathrm{F}(2,588)=8.45, \mathrm{P}$ $<.01$, partial $\eta 2=.59$, a significant effect of gender (women $\mathrm{M}=2.81, \mathrm{SD}=0.75$; men $\mathrm{M}=2.95$, $\mathrm{SD}=0.80), \mathrm{F}(1,588)=4.85, \mathrm{P}<.05$, partial $\eta 2=.60$ and a significant BMI categories by gender interaction, $\mathrm{F}(2,588)=10.95, \mathrm{P}<.01$, partial $\eta 2=.56$., with the BSS level of normal weight men were higher than their overweight and underweight counterparts, whereas underweight women were more satisfied with their bodies than women with normal weight and overweight.

Table 2. 'Ideal' Body Shape, 'Healthiest' Male and Female Body Shapes, and BID among the Respondents with the Three BMI Categories (mean \pm SD).

\begin{tabular}{lcccccc}
\hline \multicolumn{1}{c}{ BMI categories } & $\begin{array}{c}<18.5 \\
(\mathrm{n}=91)\end{array}$ & $\begin{array}{c}\text { Female } \\
(\mathrm{n}=175)\end{array}$ & $\begin{array}{c}>23.0 \\
(\mathrm{n}=26)\end{array}$ & $\begin{array}{c}<18.5 \\
(\mathrm{n}=51)\end{array}$ & $\begin{array}{c}\text { Male } \\
18.5-22.9 \\
(\mathrm{n}=188)\end{array}$ & $>23.0(\mathrm{n}=57)$ \\
\hline 'ideal' Male figure & $3.98 \pm 0.6$ & $3.95 \pm 0.8$ & $3.92 \pm 0.6$ & $4.25 \pm 0.6$ & $4.20 \pm 0.8$ & $4.32 \pm 0.7$ \\
'ideal' Female figure & $3.07 \pm 0.7$ & $3.19 \pm 0.7$ & $3.31 \pm 0.7$ & $3.59 \pm 0.7$ & $3.48 \pm 0.8$ & $3.58 \pm 0.6$ \\
the 'healthiest' Male figure & $4.17 \pm 0.7$ & $4.17 \pm 0.7$ & $3.85 \pm 0.7$ & $4.31 \pm 0.6$ & $4.26 \pm 0.7$ & $4.49 \pm 0.7$ \\
the 'healthiest' Female figure & $3.52 \pm 0.7$ & $3.61 \pm 0.6$ & $3.50 \pm 0.6$ & $3.73 \pm 0.7$ & $3.66 \pm 0.7$ & $3.72 \pm 0.6$ \\
My 'ideal' & $2.93 \pm 0.7$ & $3.16 \pm 0.7$ & $3.54 \pm 0.9 * *$ & $3.98 \pm 0.6$ & $4.11 \pm 0.7$ & $4.51 \pm 0.6 * *$ \\
My 'current' & $2.89 \pm 0.8$ & $4.07 \pm 0.8$ & $4.88 \pm 1.1$ & $2.65 \pm 1.2$ & $3.78 \pm 1.2$ & $5.53 \pm 0.8$ \\
\#BID = 'current' - 'ideal' & $0.04 \pm 0.9$ & $0.92 \pm 0.9$ & $1.35 \pm 1.0$ & $-1.33 \pm 1.3$ & $0.33 \pm 1.2$ & $1.02 \pm 0.7$ \\
No BID & $30.8 \%$ & $16.8 \%$ & $7.7 \%$ & $11.8 \%$ & $27.7 \%$ & $15.8 \%$ \\
\hline
\end{tabular}

$\mathrm{P}<0.01$ using ANOVA test

\# Negative BID value means the respondents have the desire to be bigger size.

Positive BID value means the respondents have the desire to be smaller size.

\section{Discussion}

About one-sixth of the female university students $(16.5 \%)$ in the present study were satisfied with their body shapes which lined between Japanese (9.0\%) and Taiwanese (41.3\%) female college students in the study of Shih and Kubo (2005). In the present study, female university students indicated high levels of body shape dissatisfaction, meanwhile perceived they are fat and had a desire to be thinner while they are still within the categories of underweight and normal weight. This can be explained by the studies (Basow, Foran, \& Bookwala, 2007; Davis, Karvinen, \& McCreary, 2005; Nelson, Hughes, Katz, \&
Searight, 1999) that female college students expressed negative self-evaluation, weight control by the social reinforcement and modeling during the transition period from adolescents to adult. This also confirms the findings of other studies (Chang \& Christakis, 2003; Lowry et al., 2000) investigating the perception of body weight. They found that many normal and underweight females misclassify themselves as overweight when they are not. The situation is similar with the findings of Lee and his coworkers (1996) that nearly all (90.9\%) female Chinese undergraduates with BMI above $20.5 \mathrm{~kg} / \mathrm{m}^{2}$ felt they are fat. This reflects the ideal of beauty and attractiveness in Hong Kong society is changed which was defined in a beauty pageant. According to the stature and weight information provided in the Miss Hong Kong Pageant (2013), 
the average BMI of Miss Hong Kong winners from 1973 to 2012 was 17.4, which was well below the underweight category of 18.5. In addition, there was a significant timedependent decline in BMI of Miss Hong Kong winners from 17.7 in 1980s to 17.0 in 2000s without an upward trend in stature. This shows that there is a desire for a slim body shape in Hong Kong females who attain the Western images of ideal beauty and attractiveness. The reason for desiring to be thinner suggested by Szabo and Allwood (2006) was a perception that thin women attract males and slim body shape would enable them to wear fashion clothes which are manufactured in smaller sizes only. The reason for wanting to be thinner is not investigated in the present study and it is an area of further research.

Self-perceived body shape as thin related more directly to BSS in female respondents while it is not true in their male counterparts. The highest level of BSS was observed in normal weight men and underweight women. The different perception of body shape satisfaction between male and female university students in the present study can be explained by Franzoi and Shields (1984) that body dissatisfaction was gender specific. All human societies admire large body size as a symbol of attractiveness and dominance in males (Cassidy, 1991; Ritenbaugh, 1991), while women pursuing thinness were influenced by thin media characters or models which was associated with body image dissatisfaction (Cattarin, Thompson, Thomas, \& Williams, 2000).

It is interesting to note that the majority of male and female university students did not satisfy with any parts of their body. The thigh and abdomen is the most dissatisfied body part stated by the female and male university students respectively. This finding is consistent with the earlier findings of Lee et al. (1996) with respect to body dissatisfaction of 1581 Chinese undergraduates in Hong Kong. They observed that the most dissatisfied body part stated by the female university students is the width of thigh, while the abdomen is listed the seventh out of ten most dissatisfied body parts for male counterparts. In line with the works by Shih and Kubo (2005), legs, stomach and upper thighs were the top three dissatisfied body parts stated by Taiwanese and Japanese female college students. Singh (1994) suggested that specific body parts such as hip width, abdomen and thighs may predict body shape dissatisfaction better than fatness per se. Further research is needed to increase our understanding of this uncertainty especially no satisfying body part were stated by the majority of the university students.

BMI correlates with body fatness (World Health Organization, 1998) and is one of the strongest predictors of body dissatisfaction (Cash \& Pruzinsky, 2002). In the present study, BMI significantly correlates with BID in male and female university students as well as BSS in female university students. This supports the findings of other researchers (Altabe \& Thompson, 1992; Fallon \& Rozin, 1985; Thompson, 1991; Thompson \& Psaltis, 1988; Tiggemann \& Pennington, 1990) that the greater of the discrepancy between their 'current' and their 'ideal' body shape, the higher of the level of dissatisfaction no matter it is positive or negative value. BMI is calculated by body weight and height, therefore, it is not surprise to note that the university students in the present study use their body weight to assess their body fatness.

Another findings in this study was the sizes they chose to represent the 'healthiest' figure for both genders are always significantly larger than the sizes they chose represent the 'ideal' figure in both males and females, which suggests that a larger body size is healthier than the ideal body shape perceived by the university students in Hong Kong regardless of their own BMI status. It is an area to further investigate whether the traditional Chinese culture that fat symbolizes good health is influencing the university students in the present study.

Interestingly, significant mean difference was observed on their 'ideal' figures among the three BMI categories in male and female university students. The larger size of their 'ideal' figure is selected with increasing weight status for both genders. The different standard for the university students with the different BMI categories may be explained by the study of Rand and Resnick (2000) that their acceptable body size perceptions were affected by their current body size. Further research is necessary to deepen our understanding of such biases.

Several limitations of the current study should be taken into account when interpreting the findings. First, participants came from four universities in Hong Kong and they were limited to college students. Second, the self-reported data used have limited reliability. Therefore, caution should be exercised when generalizing these findings. 


\section{Conclusions}

The study indicates that an increase in BMI aggravates an increase in BID. Weight status influenced the perception of 'ideal' figures for both genders. The size all students chose for the male and female figure representing the 'healthiest' is always larger than the 'ideal' figure they chose, regardless of their BMI and genders. The study highlights such a necessity of helping university students in Hong Kong to develop a healthy and realistic body image.

\section{Acknowledgements}

I would like to express my great appreciation to Dr. Violette Lin for her valuable suggestions during the planning and development of this research. No funding was received for this study.

\section{References}

Altabe, M., \& Thompson, J.K. (1992). Size estimation versus figural ratings of body image disturbance: Relation to body dissatisfaction and eating dysfunction. International Journal of Eating Disorders, 11, 397-402.

Bailey, S.M., Goldberg, J.P., Swap,W.C., Chomitz, V.R., \& Houser Jr., R.F. (1990). Relationship between body dissatisfaction and physical measurements. International Journal of Eating Disorders, 9, 457-461.

Basow, S.A., Foran, K.A., \& Bookwala, J. (2007). Body objectification, social pressure, and disordered eating behavior in college women: The role of sorority membership. Psychology of Women Quarterly, 3, 394-400.

Bowman, R., \& DeLucia, J. (1992). Accuracy of selfreported weight: A meta-analysis. Behavior Therapy, 23, 637-655

Brown, P.J., \& Konner, M. (1987). An anthropological perspective on obesity. Annals of the New York Academy of Science, 499, 29-46.
Bush, K.R. (2003). Commentary: Physical and mental health of contemporary Chinese children. Journal of Family and Economic Issues, 24, 397-401.

Cash, T.F., \& Pruzinsky, T. (Eds.). (2002). Body images: A Handbook of Theory, Research, and Clinical Practice. New York: The Guilford Press.

Cassidy, C.M. (1991). The good body: When big is better. Medical Anthropology, 13, 181-213.

Cattarin, J.A., Thompson, J.K., Thomas, C., \& Williams, R., (2000). Body image, mood, and televised images of attractiveness: The role of social comparison. Journal of Social and Clinical Psychology, 19, 220-239.

Chang, V.W., \& Christakis, N.A. (2003). Self-perception of weight appropriateness in the United States. American Journal of Preventive Medicine, 24(4), 332-339.

Cogan, J.C., Bhalla, S.K., Sefa-Dedeh, A., \& Rothblum, E.D. (1996). A comparison study of United States and African students on perceptions of obesity and thinness. Journal of Cross-Cultural Psychology, 26, 98-113.

Crawford, D.A., \& Worsley, A. (1988). Dieting and slimming practices of South Australian women. Medical Journal of Australia, 148, 325-331.

Davis, C., Karvinen, K., \& McCreary, D.R. (2005). Personality correlates of a drive for muscularity in young men. Personality and Individual Differences, 39, 349-359.

Davis, H., \& Gergen, P.J. (1994). Self-described weight status of Mexican-American adolescents. Journal of Adolescent Health, 15, 407-409.

Drenowski, A., Yee, D.K., Kurth, C.L., \& Krahn, D.D. (1994). Eating pathology and DSM-III-R bulimia nervosa: A continuum of behavior. American Journal of Psychiatry, 151, 1217-1219.

Drummond, M. (2002). Men, body image and eating disorders. International Journal of Men's Health, 1, 79-93. 
Fallon, A.E., \& Rozin, P. (1985). Sex differences in perceptions of desirable body shape. Journal of Abnormal Psychology, 94, 102-105.

Flynn, K.J., \& Fitzgibbon, M. (1998). Body images and obesity risk among black females: a review of the literature. Annals of Behavioral Medicine, 20(1):13-24.

Franzoi, S.L., \& Shields, S.A. (1984). The body esteem scale: Multidimensional structure and sex differences in a college population. Journal of Personality Assessment, 48, 173-178.

Hill, A. (2002). Prevalence and Demographics of Dieting. The Guilford Press, New York.

Kakeshita, I.S., \& Almeida, S.S. (2006). Relationship between body mass index and self-perception among university students. Revista de Saúde Pública, 40(3), 497-504.

Kemper, K.A., Sargent, R.G., Drane, J.W., Valois, R.F., \& Hussey, J.R. (1994). Black and white females' perceptions of ideal body size and social norms. Obesity Research, 2, 117-126.

Kenardy, J., Brown, W., \& Vogt, E. (2001). Dieting and health in young Australian women. European Eating Disorders Review, 9, 242-254.

Lee, S. (1999). Fat, fatigue and the feminine: The changing culture experience of women in Hong Kong. Culture, Medicine and Psychiatry, 23, 51-73.

Lee, S., Ho, T.P., \& Hsu, L.K.G. (1993). Fat phobic and non-fat phobic anorexia nervosa: A comparative study of 70 Chinese patients in Hong Kong. Psychological Medicine, 23, 999-1017.

Lee, S., Leung, T., Lee, A.M., Yu, H., \& Leung, C.M. (1996). Body dissatisfaction among Chinese undergraduates and its implications for eating disorders in Hong Kong. International Journal of Eating Disorders, 20, 77-84.

Leit, R.A., Pope, H.G. Jr, \& Gray, J.J. (2001). Cultural expectations of muscularity in men: The evolution of playgirl centerfolds. International Journal of Eating Disorders, 29, 90-3.
Lowry, R., Galuska, D.A., Fulton, J.E., Wechsler, H., Kann, L., \& Collins, J.L. (2000). Physical activity, food choice, and weight management goals and practices among US college students. American Journal of Preventive Medicine, 18(1), 18-27.

Miss Hong Kong Pageant (2013). Available at: http://www. misshongkongpageant.com/mhklist.htm. Cited: Jan 27, 2013.

Neighbors, L.A., \& Sobal, J. (2007). Prevalence and magnitude of body weight and shape dissatisfaction among university students. Eating Behaviors, 8, 429439.

Nelson, W.L., Hughes, H.M., Katz, B., \& Searight, H.R. (1999). Anorexics eating attitudes and behaviors of male and female college students. Adolescence, 43, 621-633.

Ng, S.K.R., \& Lin, F.P.V. (2009). Body mass index and perceptions of body among Chinese university students in Hong Kong. Medicine and Science in Sports and Exercise, 40(5), supplement, 436.

O'Dea, J., \& Abraham, S.F. (2000). Improving the body image, eating attitudes, and behaviours of young male and female adolescents: A new educational approach that focuses on self esteem. International Journal of Eating Disorders, 28, 43-57.

Priya, D., Prasanna, K.S., Sucharitha, S. \& Vaz, N.C. (2010). Body image perception and attempts to change weight among female medical students at Mangalore. Indian Journal of Community Medicine, 35(2), 316320 .

Rand, C.S.W., \& Resnick, J.L. (2000). The "good enough" body size as judged by people of varying age and weight. Obesity Research, 8, 309-316.

Ricciardelli, L.A., \& McCabe, M.P. (2001). Children's body image concerns and eating disturbance: A review of the literature. Clinical Psychology Review, $21,325-344$.

Ritenbaugh, C. (1991). Body size and shape: A dialogue of culture and biology. Medical Anthropology, 13, 173-180. 
Rozin, P., \& Fallon, A. (1988). Body image, attitudes to weight, and misperceptions of figure preferences of the opposite sex: A comparison of men and women in two generations. Journal of Abnormal Psychology, 97, 342-345.

Sakamaki, R., Amamoto, R., Mochida, Y., Shinfuku, N., \& Toyama, KA. (2005). Comparative study of food habits and body shape perception of university students in Japan and Korea. Nutrition Journal, 4(31), 31.

Shih M.Y., \& Kubo C. (2005). Body shape preference and body satisfaction of Taiwanese and Japanese female college students. Psychiatry Research, 133, 263-271.

Singh, D. (1994). Ideal female body shape: Role of body and waist-to-hip ratio. International Journal of Eating Disorders, 16, 283-288.

Stock, C., Kucuk, N., Miseviviene, I., Petkevicience, J., \& Kramer, A. (2004). Misperceptions of body shape among university students from Germany and Lithuania. Health Education, 104, 1-9.

Stunkard, A.J., Sorensen, T., \& Schulsinger, F. (1983). Use of the Danish adoption register for the study of obesity and thinness. In S. Kety (Ed.), The genetics of neurological and psychiatric disorders (pp. 115-120). New York, NY: Raven Press.

Szabo, C.P., \& Allwood, C.W. (2006). Body figure preference in South African adolescent females: A cross-cultural study. African Health Science, 6(4), 201206.

Thompson, J.K., \& Altabe, M.N. (1991). Psychometric qualities of the Figure Rating Scale. International Journal of Eating Disorders, 10, 615-619.

Thompson, J.K., \& Psalitis, K. (1988). Multiple aspects and correlates of body figure ratings: A replication and extension of Fallon and Rozin (1985). International Journal of Eating Disorders, 7, 813-818.
Thompson, J.K., (1991). Body shape preferences: Effects of instructional protocol and level of eating disturbance. International Journal of Eating Disorders, 10(2), 193-198.

Thompson, J.K., Heinberg, L.J., Altabe, M., \& Tantleff-Dunn, S. (1999). Exacting beauty. Theory, assessment, and treatment of body image disturbance. Washington, DC: American Psychological Association.

Tiggemann, M., \& Pennington, B. (1990). The development of gender differences in body-size dissatisfaction. Australian Psychologist, 25, 306-313.

Villanueva, E.V. (2001). The validity of self-reported weight in US adults: A population based crosssectional study. BMC Public Health, 1.

WHO/IASO/IOTF (2000). The Asia-Pacific Perspective: Redefining Obesity and its Treatment. Health Communication Pty Ltd: Australia.

Wiseman, C.V., Gray, J.J., \& Mosimann, J.E. (1992). Cultural expectations of thinness in women: An update. International Journal of Eating Disorders, 11, $85-9$.

World Health Organization (1998). Obesity: Preventing and managing the global epidemic. Geneva, Switzerland: WHO.

Wright, E., \& Whitehead, T. (1987). Perceptions of body size and obesity: A selected review of the literature. Journal of Community Health, 12, 117-129.

\section{Correspondence:}

\section{Robert Siu Kuen NG, PhD}

Physical Education Unit, Faculty of Education,

The Chinese University of Hong Kong, HKSAR, CHINA

Tel: (852) 39436850

Fax: (852) 26035275

E-mail: robertng@cuhk.edu.hk sarobert1218@gmail.com 